\title{
De imorais a superpredadoras: a criminalização das meninas nos Estados Unidos
}

\author{
From immorals to super-predators: \\ the criminalization of girls in the United States
}

Natália Otto

Chesney-Lind, Meda; shelden, Randall. Girls, Delinquency and Juvenile Justice. $4^{\mathrm{a}}$ ed. Oxford: Wiley \& Blackwell, 2014. 361 p.

\section{INTRODUÇÃO}

Para Adrienne Rich (1976), a empreitada intelectual feminista se resume à uma simples pergunta: “Como era para as mulheres?”. Os sociólogos norte-americanos Meda Chesney-Lind e Randall Shelden partem dessa sugestão para formular a questão que orienta sua obra: "Como é o sistema de justiça juvenil para as meninas?”. Os autores publicaram Girls, Delinquency and Juvenile Justice ("Meninas, delinquência e justiça juvenil”) pela primeira vez em 1992, nos Estados Unidos. À época, pouco se sabia sobre as meninas que adentravam o sistema de justiça juvenil do país. Assim, os autores reuniram os debates teóricos e as pesquisas empíricas mais relevantes sobre o tema já feitos até então nessa extensa obra, que ganhou status de clássico no campo dos estudos da criminalidade e da punição das mulheres. Desde sua publicação, mais pesquisadores voltaram seu foco às meninas criminalizadas, e o livro recebeu quatro reedições. Em seu vigésimo aniversário, em 2014, ele foi relançado por uma nova editora. Na nova edição da Wiley \& Blackwell, diversas passagens foram reescritas pelos autores, que incluíram novos dados e pesquisas sobre o assunto - que, de invisibilizado, tornou-se um fenômeno midiático a partir dos anos 1990. Chesney-Lind, professora do Departamento de Estudos das Mulheres da Universidade do Havaí, desde então publicou inúmeros livros e artigos sobre a criminalização das meninas nos Estados Unidos e permanece uma das principais referências sobre o tema no mundo. Shelden é atualmente professor do Departamento de Justiça Criminal da Universidade de Nevada e pesquisador do Center on Juvenile and Criminal Justice de São Francisco.

a Mestranda do Programa de Pós-Graduação em Sociologia da Universidade de São Paulo. 
Chesney-Lind e Shelden argumentam que a delinquência juvenil feminina foi tradicionalmente ignorada, tanto por pesquisadores quanto por agentes públicos norte-americanos. Pesquisadores brasileiros afirmam que o mesmo ocorre no Brasil (Assis; Constantino, 2001; Souza, 2016). Nos Estados Unidos, no entanto, essa invisibilidade passou a ser questionada a partir do final do século XX, quando a grande expansão nas prisões de meninas adolescentes não pôde ser ignorada. Entre 1991 e 2003, o número de detenções de meninas subiu 98\%, enquanto as detenções de meninos aumentaram apenas 29\%. O aumento nas apreensões policiais de meninas por crimes "tradicionalmente masculinos", como roubo e lesão corporal, também chamou a atenção de pesquisadores e da mídia para a criminalização - e a criminalidade - das adolescentes.

Segundo os próprios autores, a obra pode ser entendida como "dois livros em um”. A primeira parte aborda pesquisas sobre meninas criminalizadas, enquanto a segunda trata da história da punição das meninas e do tratamento institucional que elas recebem uma vez que adentram o sistema de justiça. Em sua ampla discussão, Chesney-Lind e Shelden têm como objetivo investigar a especificidade da experiência das meninas - tanto a natureza de seus crimes quanto os motivos pelos quais elas os cometem -, bem como o tratamento que elas recebem pelo judiciário e pelas instituições de detenção. A apresentação e a análise de dados empíricos oriundos de diversas fontes é um dos pontos fortes da obra. Por meio da mobilização desses dados, os autores conseguem confrontar mitos perpetuados pela mídia e pelas próprias ciências sociais sobre a delinquência juvenil feminina.

Em sua tese central, Chesney-Lind e Shelden argumentam que a história da punição das meninas norte-americanas pode ser entendida como a história da criminalização de suas estratégias de sobrevivência e do controle de seus corpos. Tais formas de criminalização e de controle se manifestaram de maneiras distintas ao longo da história, informadas por diferentes desenvolvimentos culturais e socioeconômicos, que vão desde as ondas migratórias do século XVIII até o pânico social diante de "adolescentes superpredadores" da década de 1990. Assim, o sistema de justiça juvenil "foi moldado pelas políticas que refletem as atitudes de uma época em relação às questões de gênero, raça e classe” (p. 184).

\section{A VIRADA DO SÉCULO: CRUZADA PARA SALVAR A INFÂNCIA E MORALIZAR AS MENINAS}

Durante o período entre 1890 e 1920, a chamada Era Progressista norte-americana, iniciou-se o processo de institucionalização do sistema de justiça juvenil do país, até então inexistente. Surgiu, nessa época, um movimento de salvação das 
crianças composto por reformistas de classe média interessados em moralizar e resgatar crianças e adolescentes “desafortunados”. Essa moralização e esse resgate tinham características específicas para as meninas. Os integrantes do movimento, muitos deles mulheres de classe média, enalteciam a família nuclear e o lugar da mulher na socialização das crianças. Ademais, advogavam pela intervenção estatal no âmbito doméstico, principalmente no que tangia ao comportamento das crianças. As aspirações dos salvadores de crianças se materializaram na criação da primeira corte juvenil dos Estados Unidos, em Chicago, em 1899.

Interessante notar que no Brasil semelhante processo ocorreu no início do século XX. Conforme Alvarez, a "cruzada pela infância” brasileira tratou de questões que iam da natalidade e da mortalidade infantil à falta de leis referentes às mulheres e às crianças (1989, p. 119). Tais preocupações levaram à emergência do Código de Menores de 1927, que previa medidas legais de intervenção estatal na vida de jovens "abandonados ou delinquentes". No que tange às mulheres adultas, pesquisas sobre processos criminais em que estas foram rés entre 1880 e 1920 demonstram a preocupação das autoridades em "impor novos padrões de conduta a esse segmento da população, padrões mais adequados à nova sociedade urbana" (Alvarez, 1996, p. 183). Souza (2016) também aponta que a criminalização das mulheres brasileiras à época era marcada pela moralização. Nesse sentido, estudos caracterizam o encarceramento feminino entre o século XIX e XX como um "reformatório de mães falhas" (SouzA, 2016, p. 133).

Nos Estados Unidos, o comportamento das meninas e das mulheres também estava no cerne das preocupações dos "salvadores da infância”. Campanhas morais para controlar a sexualidade das adolescentes surgiram, em sua maioria direcionadas às famílias de imigrantes trabalhadores, às quais eram impostos padrões de comportamento de famílias anglo-saxãs de classe média. Assim, pesquisas sobre as primeiras atividades das cortes juvenis demonstram que, nessa época, praticamente todas as meninas levadas ao tribunal eram detidas por "imoralidade". Ademais, meninas acusadas dessa conduta possuíam o dobro de chance de ser institucionalizadas, se comparadas aos meninos detidos pelo mesmo delito. Durante o processo judicial, meninas eram submetidas à exames ginecológicos, e praticamente todas que já haviam tido relações sexuais com mais de um parceiro eram institucionalizadas.

Nos Estados Unidos, "ser imoral”, assim como "ser incorrigível" e "estar fora do controle parental" são situações chamadas de ofensas de status, condutas que, embora não sejam criminalizadas na população adulta, aplicam-se aos menores de idade e autorizam intervenção estatal. Essas ofensas têm papel fundamental na 
criminalização das meninas. Segundo os autores, elas foram a primeira forma de criminalização das estratégias de sobrevivência e de controle do corpo das jovens no país. Não coincidentemente, elas são encarceradas por esse tipo de ofensa em proporções muito mais altas do que os rapazes. É importante ressaltar que jovens institucionalizados por esse tipo de conduta são muitas vezes denunciados pela própria família. Nesse sentido, Chesney-Lind e Shelden apontam que diferentes expectativas dos pais diante da obediência de meninos e meninas podem explicar a sobrerrepresentação destas nas prisões por ofensas de status.

Além das denúncias de "imoralidade", meninas eram frequentemente institucionalizadas por "fugir de casa". Até 2010, entre 10 e 20\% de todas as adolescentes apreendidas nos Estados Unidos eram "fugitivas". Semelhante ao que ocorre às consideradas "imorais", as "fugitivas" são desproporcionalmente condenadas em relação aos meninos, apesar de ambos os sexos praticarem a conduta na mesma regularidade, segundo pesquisas de autodeclaração. Assim, enquanto o controle da sexualidade era exercido a partir de denúncias de "imoralidade", as "estratégias de sobrevivência" das meninas eram controladas a partir da prisão das jovens fugitivas. Os autores trazem pesquisas que apontam que as fugas se devem, na maioria dos casos, ao sofrimento de violência doméstica - uma pesquisa realizada com meninas institucionalizadas no estado de Illinois, por exemplo, demonstrou que $95 \%$ das meninas fugitivas haviam sofrido abusos físicos e $75 \%$, abusos sexuais. Uma vez nas ruas, as adolescentes passam a cometer delitos como furtos, venda de drogas e prostituição para sobreviver. No entanto, os autores argumentam que o contexto que as leva a cometer esses delitos não é considerado pelo judiciário. Assim,

a relação entre os problemas das meninas, suas tentativas de escapar da vitimização através de fugas, e a reação tradicional do sistema de justiça juvenil é um aspecto único da interação das meninas com esse sistema (CHESNEY-Lind; SHELDEN, 2014, p. 3; em livre tradução).

Ambos os sexos - embora meninas em maior proporção - continuaram a ser institucionalizados por ofensas de status até a metade da década de 1970. Nessa época, adeptos de uma reforma do sistema de justiça juvenil argumentavam que jovens que não haviam cometido crimes deveriam ser ajudados, e não institucionalizados. Assim, a lei da "Justiça Juvenil e de Prevenção à Delinquência" de 1974 exigiu que os estados que recebiam financiamento federal para a prevenção da delinquência juvenil passassem a desinstitucionalizar jovens presos por ofensas de status. Apesar da contínua resistência das cortes juvenis, as adolescentes se bene- 
ficiaram dessa medida e seus índices de encarceramento diminuíram. No entanto, devido às pressões legislativas de conservadores, emendas foram adicionadas à lei, dificultando a desinstitucionalização. Uma emenda permitia, por exemplo, que adolescentes que "violassem ordem judicial" pudessem ser institucionalizados. Desse modo, meninas que fugiam de locais onde juízes as haviam colocado, como casas de passagem, poderiam ser encarceradas.

No prefácio da edição aqui resenhada, os autores refletem sobre o impacto dos esforços políticos pela desinstitucionalização das ofensas de status. De fato, a proporção de meninas encarceradas por esse tipo de delito diminuiu, mas elas ainda superam em muito o número de rapazes presos pelo mesmo tipo de ato. Os autores argumentam também que políticas de "tolerância zero" à delinquência juvenil implementadas na década de 1990 resultaram em um grande aumento da proporção de meninas presas por "lesão corporal", por "deturpar a paz coletiva" e por "ofensas técnicas" (como a violação de ordens judiciais). Assim, Chesney-Lind e Shelden alegam que as ofensas de status não foram desinstitucionalizadas, e sim reclassificadas como crimes pelas autoridades judiciais.

\section{A DÉCADA DE 80: A CIDADE PÓS-INDUSTRIAL E A "HIPÓTESE DA MASCULINIZAÇÃO"}

As transformações sociais que se seguiram à década de 1970 alteraram o modo como a sociedade norte-americana - tanto os setores punitivos quanto as ciências sociais - enxergava a delinquência feminina. A partir dos anos 80, perspectivas emergentes sobre a pobreza urbana passaram a ser centrais nos estudos sobre o crime, que voltaram seu foco à relação da criminalidade com as novas condições de vida nas grandes cidades, como o desaparecimento dos empregos industriais, a emergência de um novo sistema de tráfico de drogas e a combinação entre o racismo institucional e a política neoliberal. Ademais, pesquisadores da época abordaram as transformações nas relações entre masculinidade e crime nesse contexto, argumentando que a violência se tornou uma resposta racional de homens estruturalmente marginalizados. No Brasil, alguns pesquisadores também buscaram investigar a relação entre violência urbana e masculinidade. Para Zaluar (2004), por exemplo, "o etos da masculinidade, muito forte na cultura de rua [...] impõe a necessidade de responder às provocações e humilhações de modo violento" (p. 62).

Nos Estados Unidos, pesquisadores da delinquência feminina aliaram-se a essa perspectiva para explicar as experiências das meninas da periferia norte-americana. Baskin e Sommers, por exemplo, em pesquisa sobre meninas afro-americanas em Nova Iorque, apontaram que meninas negras "alcançaram" 
meninos brancos em índices de violência. Isso teria ocorrido devido às novas configurações socioeconômicas da periferia urbana dos Estados Unidos, entre elas o avanço do tráfico de drogas, que criaram "novas dinâmicas criminais nas quais o gênero é um fator menos saliente" (BASkin; Sommers; FAGAN, 1993 apud Chesney-Lind; Shelden, 2014, p. 168). Segundo essa perspectiva, o gênero perde importância e as meninas se assemelham cada vez mais aos rapazes, uma conclusão que foi chamada de "hipótese da masculinização".

No entanto, Chesney-Lind e Shelden argumentam que reforçar essa hipótese é teoricamente insuficiente e politicamente contraproducente. Os autores se preocupam com os efeitos políticos da noção de que as meninas se tornaram "tão ruins quanto os meninos", uma vez que esses discursos podem ser mobilizados para expandir o controle penal sobre as adolescentes. No campo teórico, eles defendem que a delinquência feminina, mesmo aquela que aparentemente se assemelha à masculina, deve ser sempre examinada dentro de um contexto patriarcal. Apesar de parecerem "menos salientes" em determinados contextos, as diferenças de gênero foram apenas transformadas, e não extintas. Assim, para os autores, a dominação masculina, a falta de oportunidades para as meninas e o forte controle social sobre elas, especialmente sobre seus corpos e sua sexualidade, devem continuar centrais no debate sobre a delinquência feminina.

As brigas físicas entre meninas nas periferias urbanas, por exemplo, são interpretadas pelos adeptos da "hipótese da masculinização" como um indicativo de que elas se tornaram tão violentas quanto os rapazes. A análise de Chesney-Lind e Shelden, por outro lado, aponta para o fato de que as desigualdades de gênero tornam impossível que meninas direcionem sua agressividade aos homens sem que sofram terríveis consequências. Desse modo, elas exercem sua raiva e frustração atacando outras meninas, frequentemente tendo rapazes como audiência.

Enquanto as teorias da masculinização argumentam que as meninas estão rejeitando as normas tradicionais de feminilidade, pesquisas empíricas trazidas pelos autores apontam que meninas violentas são, na verdade, mais adeptas à "ideologia patriarcal... elas apoiam o abuso de mulheres que violam os ideais de poder masculino" (DeKeseredy, 2000 apud Chesney-Lind; Shelden, 2014, p. 170). Nesse sentido, meninas que cometem violência física tendem a "comprar" crenças tradicionais de feminilidade e a "policiar" o comportamento de outras adolescentes, principalmente a partir do controle da sexualidade (como na violência contra meninas "promíscuas") e dos contratos heterossexuais monogâmicos (como na violência contra meninas que se relacionam com homens "comprometidos"). Nesse sentido, Chesney-Lind e Shelden sugerem aos pesquisadores que relacionam delin- 
quência à masculinização e à "resistência aos padrões de gênero" que investiguem mais profundamente as relações entre a violência cometida pelas meninas e o contexto de dominação masculina habitado por elas.

\section{A DÉCADA DE 90: "SUPERPREDADORES" E A EXPANSÃO DO CONTROLE SOBRE AS MENINAS}

Nos anos 1990, os discursos que circundam a hipótese da masculinização chegaram ao debate público norte-americano através da mídia, pautados pela questão: “As meninas estão alcançando os meninos?”. Nesse período, os Estados Unidos foram palco de debates midiatizados sobre delinquência juvenil, e muito se falava de jovens "superpredadores" percorrendo as cidades e assustando a população. Os questionamentos midiáticos e o pânico social consequente deles foram alimentados por dados que indicaram que, de fato, uma maior proporção de meninas estava sendo encarceradas por crimes "masculinos" (contra a vida e contra o patrimônio). Entre 1990 e 1999, as prisões de meninas por lesão corporal grave cresceram 39\%, enquanto as prisões de meninos pelo mesmo delito caíram 15\%. No entanto, Chesney-Lind e Shelden argumentam que índices de encarceramento não são suficientes para compreender esse fenômeno.

Com a diminuição do encarceramento de adolescentes de ambos os sexos por ofensas de status, o controle penal passou a agir sobre as meninas de forma diferente. Durante a década de 1990, o controle sobre o corpo através do policiamento da sexualidade deu lugar ao controle do corpo em situações de conflito físico entre meninas nas escolas. Políticas de "tolerância zero" levaram a um hiperpoliciamento das instituições escolares - processo simbolizado pelo caso de uma adolescente do estado do Arizona que sofreu uma revista íntima na escola diante de funcionários homens. Chesney-Lind e Shelden argumentam que esse policiamento levou ao encarceramento de meninas por condutas que já eram praticadas nas décadas anteriores, mas que antes não eram judicializadas, como brigas no intervalo das aulas. É importante ressaltar que meninas negras e latinas da classe trabalhadora sofreram desproporcionalmente com o aumento da repressão dos conflitos escolares, e foram, portanto, sobrerrepresentadas nos índices de encarceramento. Ainda, apesar do aumento das apreensões por atos de violência, pesquisas de autodeclaração apontam que a violência entre meninas está em queda no país.

Já os conflitos familiares, antes gerenciados pelo Estado a partir das ofensas de status, passaram a adentrar o sistema de justiça juvenil como crimes de violência. Condutas como tapas e empurrões desferidos por meninas contra seus pais, que antes seriam classificadas como ofensas de status, passaram a ser classificadas 
como lesões corporais. Como exemplo, os autores apontam o caso extremo de uma menina detida por jogar biscoitos na mãe. Um dado interessante trazido por Chesney-Lind e Shelden é o de que meninas têm mais chance de serem detidas por agredirem os pais do que meninos, o que parece comprovar a hipótese dos autores de que o fantasma das ofensas de status - e seu papel de controlar especificamente as jovens dentro do ambiente familiar - sobrevive em novos métodos de criminalização de adolescentes mulheres.

Chesney-Lind e Shelden concluem sua obra afirmando que o fenômeno da delinquência juvenil feminina nos Estados Unidos se alterou pouco ao longo dos anos, e que o cometimento de atos criminosos por meninas segue em franco declínio. Assim, há evidências de que condutas outrora consideradas ofensas de status têm sido "reclassificadas" como crimes de lesão corporal, o que fomentou a perigosa concepção social de que as meninas estão ficando "mais violentas". Os autores argumentam que são as mudanças no comportamento das instituições policias e judiciais, e não no comportamento das jovens, as responsáveis pelas transformações nas estatísticas.

\section{COMO É O SISTEMA DE JUSTIÇA JUVENIL PARA AS MENINAS BRASILEIRAS? UMA AGENDA DE PESQUISA AINDA INCIPIENTE}

Chesney-Lind e Shelden deixam importantes lições para pesquisadores brasileiros que buscam investigar o lugar das adolescentes no sistema de justiça juvenil. Entre elas, (i) a necessidade de interpretar as experiências das meninas criminalizadas dentro de um contexto de dominação masculina, evitando tomar suas práticas como "masculinas" ou "resistentes" a priori, e (ii) a importância da análise de dados empíricos sobre delinquência juvenil para além dos dados das instituições policiais, judiciais e carcerárias. Infelizmente, pesquisadores brasileiros enfrentam dificuldades em acessar dados, quaisquer que sejam, sobre meninas cumprindo medidas socioeducativas no Brasil.

Sabe-se pouco para responder à simples pergunta inicial de Chesney-Lind e Shelden: “Como é para as meninas?”. Em 2009, 604 meninas cumpriam medida socioeducativa em privação de liberdade no Brasil, em contraposição a 14.732 meninos (SDH, 2009). Já em 2013, o número de jovens mulheres internadas era de 985 , o que sinaliza um crescimento de $54 \%$. Em tal ano, as meninas eram apenas $4 \%$ de todos os adolescentes internados no Brasil (SDH, 2013). O que chama atenção é que há poucos dados disponíveis para além destes.

As poucas, porém crescentes, pesquisas qualitativas sobre o tema apontam para uma realidade próxima àquela observada por Chesney-Lind e Shelen, no 
que diz respeito ao perfil das adolescentes que adentram o sistema de justiça. As adolescentes internadas são jovens em situação de vulnerabilidade econômica e vítimas de violência intrafamiliar física e sexual (Assis; Constantino, 2001; FACHINETTO, 2008; RAMOs, 2007). No que tange às condições de internação das jovens, as descobertas empíricas também se assemelham às dos autores: com variações regionais, as casas de detenção femininas no Brasil enfrentam violações de direitos que vão desde a total ignorância das necessidades das meninas, como a presença de maternidades (CNJ, 2015), à ênfase nos papéis tradicionais de gênero, reforçados através de práticas institucionais e de cursos profissionalizantes que abrangem apenas ofícios “femininos" como costura e culinária (CNJ, 2015; FACHINETTO, 2008).

Quanto aos tipos de atos infracionais cometidos pelas adolescentes brasileiras, Fachinetto (2008) observou que há diferenças no perfil entre meninas que cometeram atos contra o patrimônio e meninas que cometeram atos de violência. As primeiras possuíam o que a autora chamou de "socialização da rua", e cometiam atos junto com grupos de amigos, sem hierarquia entre os participantes; enquanto as segundas possuíam uma "socialização da casa", e haviam cometido atos junto com figuras de autoridade masculinas. Santos (2010, 2012), analisando narrativas biográficas de adolescentes autoras de violência, aponta para a existência de variados contextos em que as meninas cometem violência física, não necessariamente em posições subalternas aos homens.

Ademais, diferentemente das mulheres adultas (SouzA, 2016), as adolescentes não estão internadas, em sua maioria, pelo ato infracional de tráfico de drogas. Pesquisa em cinco estados brasileiros realizada pelo Conselho Nacional de Justiça em 2015 revelou que o ato infracional de homicídio é responsável por grande parte das internações de meninas. No Pará, por exemplo, 60\% das adolescentes cumpriam medida socioeducativa por homicídio. São Paulo é o único dos estados pesquisados em que o ato infracional de tráfico de drogas lidera as internações, sendo responsável por 43\% delas (CNJ, 2015).

Tais dados revelam uma particularidade das meninas internadas no Brasil, muito diferente da realidade observada pelos autores nos Estados Unidos, onde as jovens são institucionalizadas por crimes leves. As meninas também se distinguem muito dos meninos brasileiros, uma vez que apenas $9 \%$ do total de jovens encarcerados no Brasil responde pelo ato infracional de homicídio. Estimulados pelas proposições de Chesney-Lind e Shelden, pesquisadores brasileiros podem se perguntar (i) que experiências de vida levam meninas a cometer atos infracionais violentos, e (ii) que práticas policiais e judiciais podem explicar os altos índices de encarceramento de meninas por homicídio. Embora a prática de violência física 
por parte de meninas aparente ser um fenômeno social de baixa incidência no Brasil, Chesney-Lind e Shelden demonstram que pesquisas sobre o tema podem revelar importantes transformações na criminalidade, bem como nas dinâmicas das relações de gênero.

\section{REFERÊNCIAS BIBLIOGRÁFICAS}

Alvarez, Marcos César. A Emergência do Código de Menores de 1927: Uma análise do discurso jurídico e institucional de assistência e proteção aos menores. Dissertação (Mestrado) - Universidade de São Paulo. Faculdade de Filosofia, Letras e Ciências Humanas. Programa de Pós-Graduação em Sociologia, São Paulo, SP-BR, 1989.

. Bacharéis, Criminologistas e Juristas: Saber jurídico e nova escola penal no Brasil (1889 - 1930). Tese (Doutorado) - Universidade de São Paulo. Faculdade de Filosofia, Letras e Ciências Humanas. Programa de Pós-Graduação em Sociologia, São Paulo, SP-BR, 1996.

Assis, Simone; Constantino, Patrícia. Filhas do mundo: infração juvenil feminina no Rio de Janeiro. Rio de Janeiro: Editora Fiocruz, 2001.

Conselho Nacional de Justiça [CNJ]. Dos espaços aos direitos. Brasília, 2015.

Fachinetto, Rochele Fellini. A "casa de bonecas": um estudo de caso sobre a unidade de atendimento socioeducativo feminino no RS. Dissertação (Mestrado) - Universidade Federal do Rio Grande do Sul. Instituto de Filosofia e Ciências Humanas. Programa de Pós-Graduação em Sociologia, Porto Alegre, BR-RS, 2008.

Ramos, Malena. Meninas privadas de liberdade. Dissertação (Mestrado) - Pontifícia Universidade Católica do Rio Grande do Sul. Faculdade de Serviço Social. Programa de Pós-Graduação em Serviço Social, Porto Alegre, BR-RS, 2007.

Rich, Adrienne. Of Women Born. New York: Norton, 1976.

SANTos, Hermílio. Adolescents and Experiences with Violence: making sense of subjective interpretations of life-world. Vibrant, v. 7, n. 2, 2010.

Ação e relevância em narrativas de adolescentes autoras de atos infracionais. Contemporânea, v. 2, n. 2, p. 489-512, 2012.

Secretaria de Direitos Humanos [SDH]. Atendimento Socioeducativo ao Levantamento Nacional do Atendimento Socioeducativo ao Adolescente em Conflito com a Lei. Brasília, 2009.

Levantamento Anual SINASE 2013. Brasília, 2013.

SouzA, Luís Antônio. As contradições do confinamento no Brasil. Sociedade em Debate, v. 22, n. 2, p. 127-156, 2016.

ZALUAR, Alba. Integração perversa: pobreza e tráfico de drogas. Rio de Janeiro: Fundação Getúlio Vargas, 2004. 